\title{
Pembinaan Seni Pertunjukan dan Seni Rupa di Desa Rambeanak
}

\author{
Dindin Heryadi ${ }^{1}$, Ismael Setiawan ${ }^{2}$ \\ ${ }^{1}$ Jurusan Tari, Fakultas Seni Pertunjukan \\ ${ }^{2}$ Program Studi Desain Komunikasi Visual, Fakultas Seni Rupa \\ Institut Seni Indonesia Yogyakarta \\ Jalan Parangtritis Km 6,5, Sewon, Bantul, Daerah Istimewa Yogyakarta 55188 \\ No. Hp.: ${ }^{1}+62818462834,{ }^{2}+628122736427$ \\ E-mail: ${ }^{1}$ dinheryadi@gmail.com, ${ }^{2}$ ismael_bidisi@yahoo.com
}




\title{
Pembinaan Seni Pertunjukan dan Seni Rupa di Desa Rambeanak
}

\author{
Dindin Heryadi ${ }^{1}$, Ismael Setiawan ${ }^{2}$ \\ ${ }^{1}$ Jurusan Tari, Fakultas Seni Pertunjukan \\ ${ }^{2}$ Program Studi Desain Komunikasi Visual, Fakultas Seni Rupa \\ Institut Seni Indonesia Yogyakarta \\ Jalan Parangtritis Km 6,5, Sewon, Bantul, Daerah Istimewa Yogyakarta 55188 \\ No. Hp.: ${ }^{1}+62818462834,{ }^{2}+628122736427$ \\ E-mail: ${ }^{1}$ dinheryadi@gmail.com, ${ }^{2}$ ismael_bidisi@yahoo.com
}

\begin{abstract}
Abstrak
Terdapat lima kelompok di Desa Rambeanak, yaitu kelompok kesenian Satrio Gedruk Walijo, kelompok Hadroh, kelompok Srodut Sanggar Bina Muda, Alkaloid Farm, dan Karang Taruna. Sayangnya, belum ada pelatih di tiap kelompok yang mengakibatkan kurang efektifnya kegiatan yang dilaksanakan di tiap kelompok. Pembinaan seni ini dilaksanakan dengan menggunakan metode ceramah dan praktik. Kegiatan P3 Wilsen di Desa Rambeanak menghasilkan karya-karya baru baik tari, karawitan, serta batik dan kaos ciri khas Rambeanak. Diharapkan dengan karya-karya tari, karawitan, batik, dan sablon ini bisa dijadikan materi masing-masing sanggar untuk kegiatan berkesenian khususnya di daerah Kabupaten Magelang agar bisa menambah pendapatan secara ekonomi bagi masing-masing peserta kegiatan.
\end{abstract}

Kata kunci: seni rupa, seni pertunjukan, Rambeanak

\section{Performing Arts and Fine Arts Coaching in Rambeanak Village}

\section{Abstract}

There are five arts group in Rambeanak Village, which are; Satrio Gedruk Walijo, Hadroh, Srodut Sanggar Bina Muda, Alkaloid Farm, and Karang Taruna (local youth) group. Unfortunately, there is yet an experienced coach in each group that resulted in the group's inefficient activity. The arts coaching methods are done through lecture and practice. The P3Wilsen in Rambeanak Village produces new art works like dances, karawitan, also Batik and Ramebanak specialty shirt. It is hoped that the 5 art groups' activity can improve through these products (dance, karawitan, batik, and prints), especially in Magelang Regency to increase their financial income for their respective group members.

Keyword: fine art, performing art, Rambeanak 


\section{PENDAHULUAN}

Rambeanak adalah sebuah desa di Kecamatan Mungkid, Kabupaten Magelang, Provinsi Jawa Tengah, sebuah kawasan sejuk, damai, dan tenteram. Kawasan subur dan cocok untuk ditanami berbagai tanaman sayuran dan tembakau. Desa yang dengan mudah diakses dari jalan raya karena letak desanya yang tidak jauh dari jalan raya atau jalan utama antara jalan Yogyakarta-Magelang dan tidak jauh dari ibu kota Magelang. Desa ini dapat diakses dari kawasan pariwisata Candi Mendut, Candi Pawon, dan tentunya Candi Borobudur, yang merupakan salah satu dari 7 bangungan dari keajaiban dunia. Jarak antara Candi Borobudur dan Desa Rambeanak hanya sekitar 5 kilometer. Sebagian besar penduduknya adalah petani dan pedagang. Banyak kegiatan kesenian dan kebudayaan di Desa Rambeanak yang menyatu dalam kehidupan masyarakat, menarik untuk dipelajari karena di wilayah ini antara ritus desa dan kesenian, kegiatan muda-mudi, dan kesuburan alam masih tetap dijaga. Potensi kesenian tradisi yang ada di Desa Rambeanak di antaranya Kubrosiswo, Gedruk, Kubro Dangdut (Brodut), dan Rebana.

Pertama, Kelompok Brodut Sanggar

Bina Muda berlokasi di Dusun Rambeanak dengan beranggotakan seniman muda. Komunitas ini mampu mengoordinasi kegiatan seni yang ada di sana. Kesenian Brodut merupakan perkembangan kesenian Kubro Siswo yang menggunakan gamelan/alat musik berupa bedug, bende, seruling, tamborin, dan rebana yang rata-rata berirama mars. Di Wilayah Kabupaten Magelang, Kubro Siswo telah berhasil berkolaborasi dengan musik dangdut yang kemudian menjadi familiar dengan sebutan Kubro Dangdut atau disingkat Brodut. Kesenian ini terdapat penari yang berjumlah antara 12 - 24 penari. Kelompok Brodut Sanggar Bina Muda memerlukan pelatih tari untuk bisa memberikan ilmu tentang koreografi kelompok. Seperti diketahui bahwa brodut ini merupakan tarian yang ditarikan secara kelompok sehingga perlu diberikan agar tarian yang ada di brodut ini terkesan tidak monoton.

Kedua, kelompok kesenian Satrio Gedruk Walijo berlokasi di Dusun Rambeanak 2. Kelompok ini merupakan kelompok kesenian yang sudah lama berdiri hanya perkembangannya mengalami stagnan. Hal ini disebabkan tidak adanya pelatih karawitan, tari, dan juga struktur organisasi yang baik. Anggota kelompoknya didominasi oleh anak muda.

Ketiga, kelompok hadroh berlokasi di Dusun Jetis, Desa Rambeanak. Kelompok ini masih sering melakukan pentas di sekitar Kecamatan Mungkid. Kelompok hadroh memerlukan pelatih musik agar bisa memberikan kreasi baru dalam kelompok ini. Keempat, Karang Taruna di Desa Rambeanak merupakan wadah pengembangan generasi muda nonpartisan, yang tumbuh atas dasar kesadaran dan rasa tanggung jawab sosial dari, oleh, dan untuk masyarakat khususnya generasi muda di wilayah desa/kelurahan atau komunitas sosial sederajat, yang terutama bergerak di bidang kesejahteraan sosial. Sebagai organisasi sosial kepemudaan, Karang Taruna merupakan wadah pembinaan dan pengembangan serta pemberdayaan dalam upaya mengembangkan kegiatan ekonomi produktif dengan pendayagunaan semua potensi yang tersedia di lingkungan baik sumber daya manusia maupun sumber daya alam yang telah ada. Sebagai organisasi kepemudaan, Karang Taruna didirikan dengan tujuan memberikan pembinaan dan pemberdayaan kepada para remaja, misalnya dalam bidang keorganisasian, ekonomi, olahraga, ketrampilan, advokasi, keagamaan, dan kesenian. Agar bisa meningkatkan kemampuan atau skill dari anggotanya, yang nantinya bisa meningkatkan ekonomi 
masyarakat dan juga menjadi alternatif untuk memulai usaha, diperlukan instruktur dalam hal cara membuat batik dan sablon.

Kelima, berawal dari sebuah kelompok tani di Desa Rambeanak yang selanjutnya mempunyai inisiatif untuk mengembangkan wisata pertanian dengan membuat sebuah tempat yang diberi nama Alkaloid Farm. Tempat ini sedang merintis sebuah tempat wisata edukasi pertanian. Tempat ini berada di tengah sawah yang tujuannya adalah memberikan pengetahuan kepada masyarakat tentang nama-nama pohon buah yang ada di tanah air. Di lokasi ini dibuat sebuah tempat untuk pementasan kesenian yang tujuannya untuk menghibur semua pengunjung yang hadir ke Alkaloid Farm. Untuk memenuhi rencana kelompok tani yang akan membuat tempat wisata edukasi pertanian itu diperlukan tarian yang khusus untuk disajikan kepada pengunjung. Dengan demikian, dibutuhkan sebuah tarian baru yang dibuat khusus untuk sajian tersebut.

Oleh karena itu, kegiatan ini memberikan solusi, yaitu (1) memberikan pelatihan tari dan karawitan terutama dalam hal pengetahuan tentang koreografi kelompok; (2) memberikan pembinaan dan pelatihan di bidang tari dan karawitan; (3) memberikan pembinaan dan pelatihan di bidang musiik hadroh; (4) memberikan pelatihan batik dan sablon; dan (5) membuat tari yang khusus untuk disajikan kepada pengunjung Alkaloid Farm.

\section{METODE PENGABDIAN}

Kegiatan P3 Wilsen di Kecamatan

Ngluwar, Kabupaten Magelang ini

menggunakan berbagai metode, di antaranya metode praktik dan metode ceramah. Metode praktik adalah penerapan materi gerak tari, musik tari, mencanting, dan sablon kepada peserta kegiatan. Metode ini memberikan gerak-gerak tari dan teknik menabuh gamelan kepada para peserta kegiatan yang diharapkan lebih terasah baik tubuh maupun dalam melakukan teknik menabuh dan juga agar terampil dalam membatik dan menyablon. Metode ceramah digunakan untuk menerangkan berbagai istilah dalam dunia tari dan musik tari serta pengenalan dan teknik yang ada dalam membatik dan juga menyablon. Seperti berkaitan dengan istilah dalam tari, sejarah tari yang diajarkan, nama-nama gerak, istilah dalam karawitan, istilah dalam membatik, dan juga istilah dalam menyablon.

\section{HASIL DAN PEMBAHASAN}

Khalayak yang menjadi sasaran adalah anggota Sanggar Bina Muda Rambeanak dengan jumlah 20 orang, anggota Kelompok Sanggar Satrio Gedruk Walijo dengan jumlah 10 orang, 9 orang anggota Kelompok Hadroh, Kelompok Karang Taruna yang dibagi menjadi 2 bidang, yaitu sablon sejumlah 3 orang dan batik berjumlah 9 orang, dan 18 anggota Kelompok Tani Alkaloid Farm. Materi kegiatan dalam Sanggar Bina Muda Rambeanak (Brodut) adalah observasi latihan brodut untuk menginventarisasi masalah, melatih kekompakan gerak, pemahaman pola lantai, memperbaiki detail bagian per bagian baik musik maupun tari, melatih kekompakan gerak, dan rekaman. Gambar 1 adalah foto kegiatan di Sanggar Bina Muda Rambeanak. 


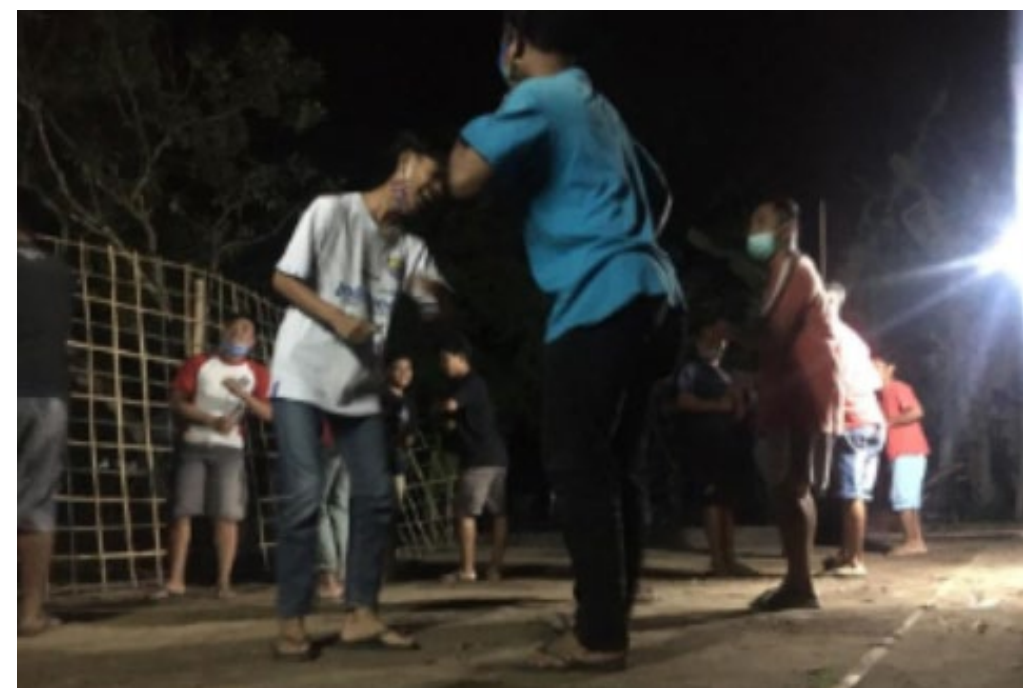

Gambar 1 Kegiatan di Sanggar Bina Muda Rambeanak

Materi untuk kelompok Sanggar Satrio Gedruk Walijo adalah observasi tari dan musik terutama pada tempo dan peralihan, pelatihan tari kreasi baru putra, pengolahan detail gerak pada motif sabetan tari kerakyatan
Gedruk, pengolahan musik gedruk intro dan adegan 1, pengolahan pola lantai, tempuk gending, dan rekaman. Gambar 2 adalah foto kegiatan di Sanggar Satrio Gedruk Walijo.

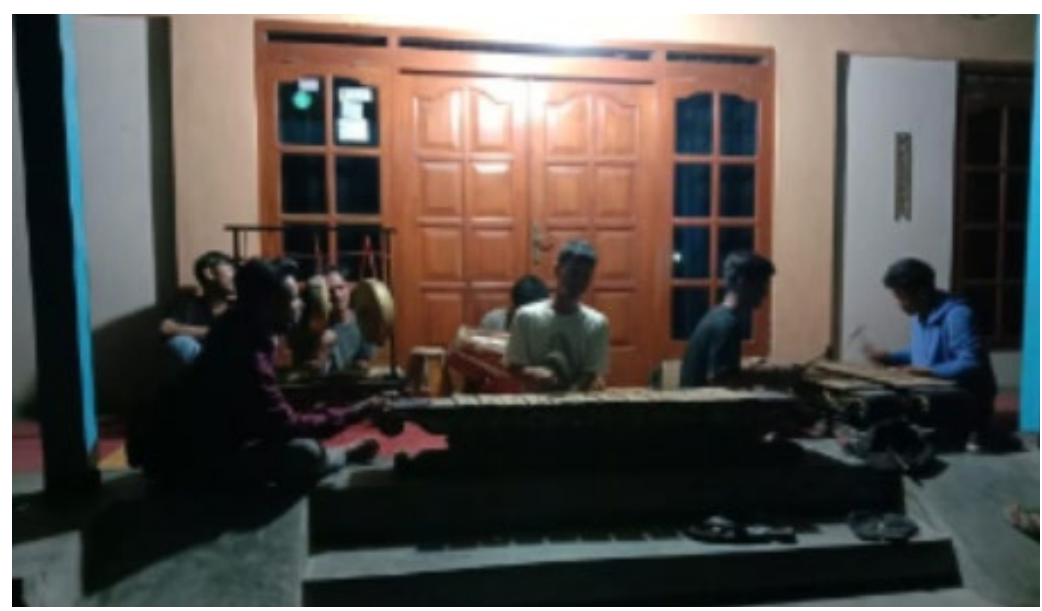

Gambar 2 Kegiatan di Sanggar Satrio Gedruk Walijo

Materi untuk kelompok Hadroh adalah aransemen ulang lagu yang sudah pernah dimainkan. Gambar 3 adalah foto kegiatan di kelompok Hadroh. Hingga saat ini kesenian hadroh sudah melekat dalam masyarakat, salah satunya sebagai sebuah eksistensi budaya Islam yang harus selalu dijaga dan dikembangkan (Ahmad, 2013:28). 


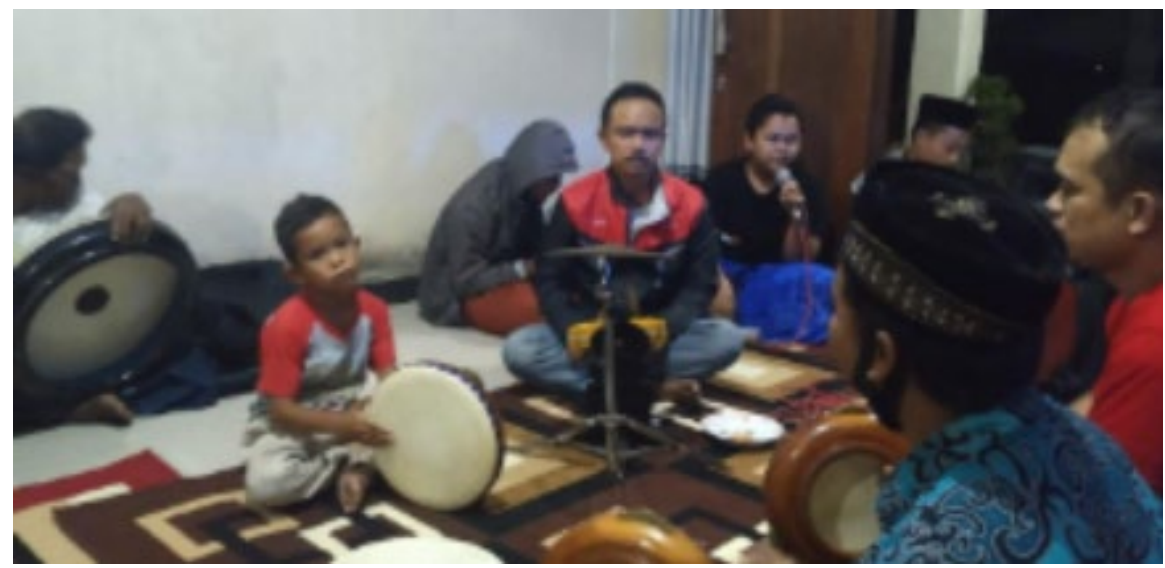

Gambar 3 Kegiatan di Kelompok Hadroh

Materi untuk Karang Taruna Desa Rambeanak di bidang batik adalah pengenalan dasar batik tulis, mencanting motif pada kain ukuran $30 \mathrm{~cm}$ x $30 \mathrm{~cm}$, mencanting motif pada kain ukuran $1 \mathrm{~m}$ x $1 \mathrm{~m}$, mencanting dan mewarna remasol dengan teknik colet, mewarna batik teknik celup dengan pewarna indigosol dan naptol, mewarna teknik usap dengan pewarna remasol, menutup bagian motif, dan lorod malam pada batik. Zat warna sintetis yang bisa digunakan dalam batik adalah zat warna napthol, indigosol, dan remasol (Supriono, 2016:204). Menurut Susanto (1974:164) pewarnaan teknik colet perlu memperhatikan hal-hal berikut: (1) larutan zat warna dengan konsentrasi tinggi, pada keadaan dingin dicoletkan pada kain dengan bidang yang akan diberi warna dibatasi malam dengan baik; (2) dikeringkan, dengan dibiarkan terbuka agak lama hingga kering betul; (3) difiksasi atau dibangkitkan warna menurut jenis zat warna yang digunakan dalam pewarna. S

Di bidang sablon dilakukan pengenalan sablon manual, dasar desain, membuat desain sablon, pemindahan desain ke screen penyiapan pasta pewarna dan penyiapan alat sablon, teknik perakelan, teknik pengeringan, dan teknik pencucian screen. Gambar 4 adalah foto kegiatan di Karang Taruna Desa Rambeanak

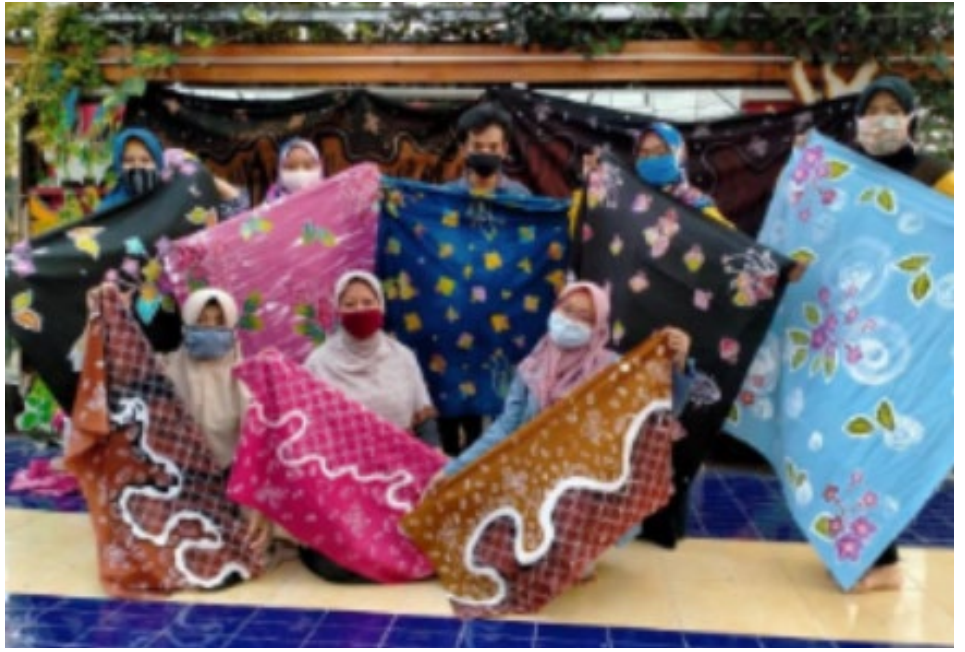

Gambar 4 Kegiatan membatik di Karang Taruna Desa Rambeanak 
Materi pada Kelompok Tani Alkaloid Farm adalah pengolahan pola lantai, penyamaan gerak, detail gerak, dan pola lantai serta penyatuan gerakan dengan musik Gambar 5 adalah foto kegiatan di Kelompok Tani Alkaloid Farm.

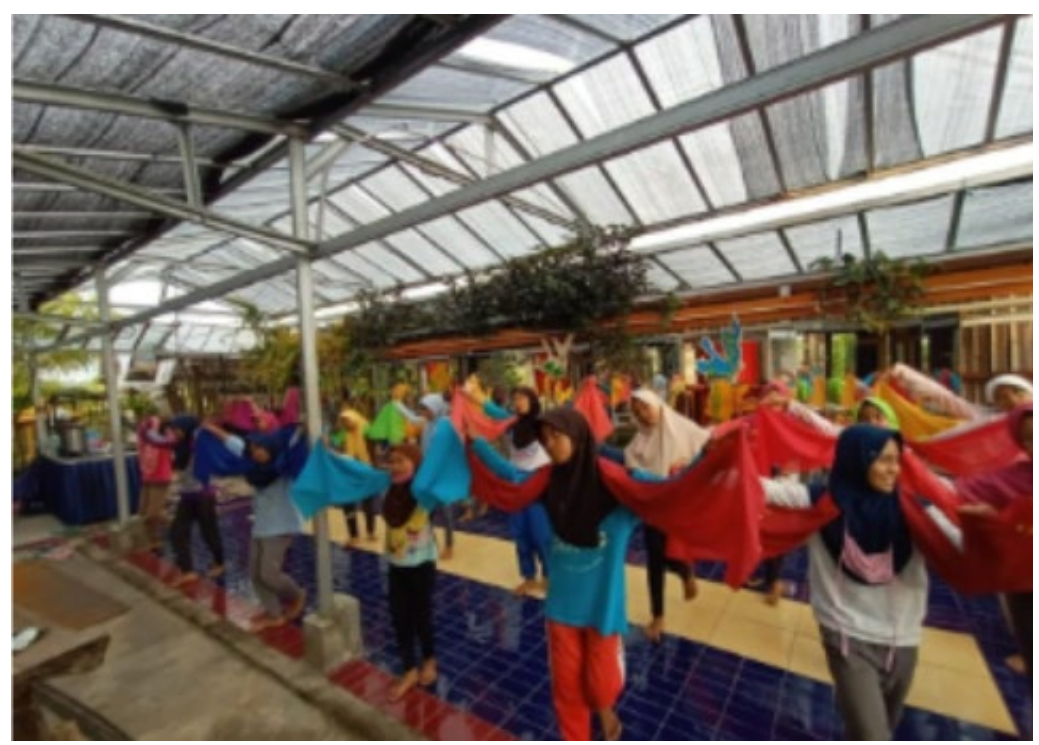

Gambar 5 Kegiatan di Kelompok Tani Alkaloid Farm

Kegiatan P3 Wilsen di Desa Rambeanak menghasilkan karya-karya baru baik tari, karawitan, batik khas Rambeanak, dan juga kaos ciri khas Rambeanak. Diharapkan dengan karya-karya tari, karawitan, batik, dan sablon ini bisa dijadikan materi masing-masing sanggar untuk kegiatan berkesenian khususnya di daerah Kabupaten Magelang yang bisa menambah pendapatan secara ekonomi bagi masing-masing peserta kegiatan.

Manfaat kegiatan ini bagi mahasiswa adalah mendapatkan pengalaman mengaplikasikan hasil dari proses pembelajaran di kampus, memberikan pengalaman dan keterampilan kepada mahasiswa sebagai kader pembangunan, membentuk sikap dan rasa cinta, kepedulian sosial dan tanggung jawab mahasiswa terhadap kemajuan masyarakat, membina mahasiswa menjadi seorang motivator, inovator, dan problem solver. Bagi dosen dapat menambah jejaring dengan seniman tradisi, menambah pengetahuan tentang kesenian rakyat yang berkembang di Kecamatan Ngluwar, Kabupaten Magelang.
Bagi Masyarakat dan pemerintah adalah pemberian bantuan pemikiran dan tenaga dalam pemecahan masalah pembangunan daerah setempat khususnya bidang kesenian serta tumbuhnya dorongan potensi dan inovasi di kalangan anggota masyarakat khususnya kelompok kesenian setempat dalam upaya meningkatkan keterampilan anggotanya.

\section{SIMPULAN}

Masyarakat dan pemerintah di Desa Rambeanak sangat antusias dalam mendukung program kerja P3 Wilsen yang dibuktikan dengan kesediaan waktu dan keaktifan mereka untuk turut berpartisipasi dalam kegiatan-kegiatan yang diadakan oleh tim P3 Wilsen di Desa Rambeanak. P3 Wilsen merupakan salah satu bentuk pengabdian kepada masyarakat yang masih dibutuhkan masyarakat. Ini terbukti dengan banyaknya masyarakat yang meminta kegiatan serupa di tempat atau sanggar lain pada tahun-tahun yang akan datang. Program kerja yang efektif adalah program yang langsung bersentuhan dengan 
masyarakat dan sesuai dengan kondisi yang ada sehingga pada akhirnya nanti masyarakat akan dapat merasakan hasil dari program tersebut. Kegiatan P3 Wilsen di Desa Rambeanak sangat bermanfaat bagi mahasiswa yang melaksanakannya sebagai modal awal untuk terjun ke masyarakat dan manfaatnya pun bisa langsung dirasakan oleh masyarakat. Pemahaman yang komprehensif terhadap karakter, budaya, dan kondisi sosial masyarakat tempat lokasi P3 Wilsen mutlak dibutuhkan, sebagai bagian dari upaya untuk mempercepat proses adaptasi dan sosialisasi. Komunikasi yang baik antara Tim P3 Wilsen dan pemerintah desa, remaja dan pemuda desa, serta segenap warga Desa Rambeanak juga menjadi faktor terpenting dalam kelancaran dan keberhasilan pelaksanaan program. Komunikasi yang terjalin dapat mempermudah koordinasi sehingga tidak menimbulkan kesalahpahaman.

\section{SARAN}

Kerja sama dalam pelaksanaan program yang terjalin antara masyarakat dan mahasiswa P3 Wilsen selama ini diharapkan dapat ditindaklanjuti dan dimanfaatkan secara optimal oleh masyarakat setempat. Selain itu, perlu adanya kesinambungan program dan koordinasi sehingga kegiatan yang sudah dilaksanakan di Desa Rambeanak ini bisa berjalan dengan baik dan lancar.

\section{UCAPAN TERIMA KASIH}

Penulis mengucapkan terima kasih kepada Lembaga Penelitian dan Pengabdian Masyarakat Institut Seni Indonesia Yogyakarta yang telah memberi dukungan terhadap keberhasilan pengabdian ini.

\section{DAFTAR PUSTAKA}

Ahmad, Amirullah. (2013). Dakwah Islam dan Transformasi Sosial Budaya. Yogyakarta: PLP2M.

Supriono, Primus. (2016). The Haritage of Batik Identitas Pemersatu Kebanggaan Bangsa. Yogyakarta: CV Andi Offset.

Susanto, Sewan. (1974). Seni Kerajinan Batik Indonesia. Jakarta: Balai Penelitian Batik dan Kerajinan, Lembaga Penelitian, Departemen Perindustrian RI. 